\title{
Do Criminal Sanctions Deter Insider Trading?
}

\author{
Bart Frijns, Aaron Gilbert", Alireza Tourani-Rad \\ Department of Finance, School of Business and Law, Auckland University of Technology, \\ Auckland, New Zealand
}

* Corresponding Author. Aaron Gilbert, Department of Finance, Auckland University of Technology, Private Bag 92006, 1020 Auckland, New Zealand, Email: agilbert@aut.ac.nz, phone: +649921 5713, fax: +6499219940. 


\title{
Do Criminal Sanctions Deter Insider Trading?
}

\begin{abstract}
Many developed markets have taken what appears to be a tough stance on illegal insider trading through the use of criminal sanctions. Although criminal sanctions represent a much greater penalty than civil sanctions, the higher burden of proof required makes their enforceability weaker. This trade-off between severity and enforceability makes the impact of criminal sanctions ambiguous. In this paper, we empirically examine this issue by studying the deterrence of insider trading following the introduction of criminal sanctions in a developed market. Significant changes in sanction regimes are rare, especially when criminal sanctions are introduced without other changes. In February 2008, New Zealand introduced criminal sanctions for insider trading. This change of law offers a unique setting in which to examine the deterrence effect of criminalization. Using measures for the cost of trading, degree of information asymmetry, and probability of informed trading, we find that the enactment of this law led to a worsening in these measures. These findings suggest that the weaker enforceability of criminalization outweighs the associated increased severity of the penalties.
\end{abstract}

JEL Codes : C22, D82, G18

Key Words: Market Microstructure, Bid-Ask Spreads, Information Asymmetry, Insider Trading, Criminal Sanctions 


\section{Introduction}

Deterrence of prohibited activities is a function of both the severity of the punishment (sanctions) and probability of detection and prosecution (enforcement) (Becker, 1968). As a result, it is important for law makers when developing laws to consider both severity and enforceability of the laws. In finance, this debate has largely evolved around the issue of illegal insider trading, where different countries have developed different approaches in an attempt to deter corporate insiders from expropriating their shareholders. However, as noted by Bhattacharya and Daouk (2009), for insider trading laws to be effective they must be enforceable, and if they are not enforced, a country may actually be better off with no laws at all.

In policy discussions around insider trading (although insider trading can be both legal and illegal, in this paper we use the term insider trading to refer to illegal insider trading), the issue of severity versus enforceability has often focused on the type of sanctions imposed. Criminal sanctions present a much stronger penalty than civil sanctions given the potential for jail sentences in addition to the stigma of a criminal conviction if the prosecution is successful. However, the burden of proof required (i.e. the level of certainty required for a guilty verdict to be delivered) is also significantly higher in a criminal case. ${ }^{1}$ Therefore, while criminal sanctions offer more severe penalties, they are also less likely to result in a successful prosecution. This view was clearly articulated in a speech by members of the US Securities Exchange Commission in 1998, where they argued that illegal insider trading is largely inferential. Cases are often based around circumstantial evidence relating to meetings, phone calls and presumed possession of information, making it difficult to establish guilt to the criminal standard, beyond a reasonable doubt (Newkirk and Robertson, 1998). A similar point of view was recently stressed by the Chairman of the Australian Securities and Investment Commission who noted that despite recent successful criminal prosecutions, the burden of proof and the evidence required remained problematic (D'Aloisio, 2010). He referred to a quote from Duffy (2009) exploring issues around the burden of proof:

\footnotetext{
${ }^{1}$ Civil cases in common law jurisdictions are decided on the balance of probabilities, requiring it to be only more likely than not that an offence was committed. Criminal cases are decided on the "beyond a reasonable doubt" test, a much tougher burden to meet, especially when prosecuting on the basis of largely circumstantial evidence as is often the case for insider trading.
} 


\begin{abstract}
"Regulators will often find themselves in a position where they can identify a person with inside information on a particular security, a person who traded in that security, a relationship between the two persons and even evidence of communications between them (such as telephone records). This however may still not be enough unless there is some evidence of the content of the communications and, in particular, the conveying of price sensitive information that was not generally available. Further, though a circumstantial case for communication may exist, it is usually necessary to establish what was said to identify it as price sensitive information. Also, given the seriousness of such an allegation it is unlikely that evidence of such communication can be inferred from the surrounding circumstances” Duffy (2009) pg. 155
\end{abstract}

The implication of this statement is that mere circumstantial evidence of possession of information, and communication with another person who then trades in a manner consistent with that information is not enough if the content of the communication itself is not known. Additionally, traders can point to 'explanations' which, while improbable, may be sufficient to create reasonable doubt.

The case of Martha Stewart in the US illustrates the actual difficulties in achieving criminal convictions for insider trading. Stewart received information from her broker regarding trading in Imclone by the CEO. Based on that information, Stewart sold 4,000 shares shortly before a major announcement resulting in Stewart avoiding losses of $\$ 45,673$. Stewart faced both civil and criminal cases for her involvement. Her defence was based on a fictitious limit order to sell if Imclone dropped below $\$ 60$. While Stewart was indicted on 9 charges including insider trading, the insider trading charges were dropped before the criminal case was heard. In contrast, her civil case resulted in an out-of-court settlement on the insider trading allegation which saw her receive a 5-year ban from acting as a director, repaying her gains of $\$ 45,673$ plus interest and a pecuniary penalty of three times the loss avoided (US Securities and Exchange Commission, 2006).

The example of Martha Stewart illustrates the trade-off between severity and enforceability and demonstrates that there is an ambiguous effect on the deterrence of insider trading. This 
ambiguous effect exists when criminal sanctions replace civil sanction, but also when criminal sanctions and civil sanctions co-exist. As Bhattacharya and Daouk (2009) argue, if a law is enacted but not enforced it will deter some insider from trading illegally. However, those that are not deterred will trade with greater intensity (see also Bris, 2005). This may also apply to the situation where criminal sanctions are introduced in addition to civil sanctions. The addition of criminal sanctions may deter some insiders who were not deterred by the weaker civil sanctions, but those that are not deterred will trade with greater intensity. Overall, as suggested by Bhattacharya and Daouk (2009), enforceability is key. If insiders see the laws as being enforceable market quality will improve, if not market quality may deteriorate.

In this paper, we examine the deterrence effect following the introduction of criminal sanctions on insider trading. Major changes in sanction regimes are exceptional, especially when criminal sanctions are introduced without other significant changes. In February 2008, the New Zealand government enacted the Securities Market Amendment Act 2006 (SMAA), which introduced criminal sanctions. This offers a unique setting to examine the deterrence effect of criminalization. ${ }^{2}$ Prior to this act, the law allowed for civil penalties of three times the value of the gain made or loss avoided or one million dollars, whichever is greater. The SMAA introduced a maximum penalty of 5 years imprisonment and/or a NZ\$300,000 fine for an individual found guilty of insider trading. We study this change in legislation to determine whether the criminalization of insider trading has been beneficial.

To empirically investigate the impact of these new laws, we collect data for the most liquid companies on the New Zealand Stock Exchange (NZX) for twelve-, six- and three-month windows around the enactment date, 29 February 2008. We examine a range of information asymmetry measures, specifically the percentage spread, the effective spread, the price impact of trades, the proportion of information asymmetry by Lin et al. (1995), and the probability of informed trading (Easley et al., 1996, 1997a, 1997b). ${ }^{3}$ Using an event study type of methodology, we explore changes in these measures before and after the enactment of

\footnotetext{
${ }^{2}$ During the event window studied no other securities bills were enacted or passed into law.

${ }^{3}$ These measures have previously been used to examine changes in insider trading laws in Gilbert et al. (2007) and Frijns et al. (2008)
} 
the SMAA. The results for all measures indicate that the introduction of criminal sanctions has led to a statistically significant increase in the cost of trading and the proportion of information asymmetry. These results are also economically significant, where the effective spread has increased by an average of $63 \%$ in the period from twelve months before the enactment to twelve months after the enactment. To ensure the robustness of these results, we sort our sample into firms that are most and least likely to be affected by the reforms (liquid vs. illiquid and high vs. low information asymmetry) and examine the effect on our informed trading measures. The results, when sorted on trading activity, reveal that illiquid firms see the biggest deterioration in the informed trading measures. Lastly, we employ a difference-indifference approach using a control sample of similar Australian firms, who are not subject to the sanction regime in New Zealand, to control for other potential market-wide effects. These results confirm that the introduction of criminal sanctions has failed to improve the efficiency of the market, and has in fact made it worse.

Overall, our findings suggest that the change in legislation has reduced the deterrence effect of the laws. Since there has been no enforcement of insider trading laws in New Zealand, our findings also support Bhattacharya and Daouk's (2009) hypothesis that no law may be better than a good law when enforcement is poor. Given the popularity and widespread use of criminal sanctions to deter insider trading and the lack of empirical evidence on their efficacy, these findings may have considerable policy implications for many countries.

The remainder of the paper is organized as follows. Section 2 discusses the literature and introduces the New Zealand market and its insider trading regulations. Section 3 presents the microstructure measures that we employ and discusses the sample. Section 4 presents the paper's findings and Section 5 concludes.

\section{Background}

\subsection{Literature Review}

Criminal sanctions for illegal insider trading have been introduced in many countries. Beny (2004) finds criminal sanctions in 27 out of 36 countries in her sample, and more recently, Frijns et al. (2010) find that these sanctions are present in 26 out of 31 countries in their 
sample. This popularity has largely been driven by the perception of lawmakers and market observers that criminal sanctions offer a greater deterrence than civil penalties. For example, after its introduction of a criminal-only regime, the Dutch regulators lauded their approach as the "toughest regime" (Financial Times, 1998). In addition, Joo (2007) argues that increasing criminal sanctions satisfies the appearance of being tough on market manipulation by sending a message that insider trading will be treated extremely seriously. This also conforms with Easterbrook (1985), who suggests that the threat of imprisonment may lead to optimal deterrence. A discussion paper by the New Zealand Ministry of Economic Development notes that criminal penalties may carry a stigma that civil prosecution does not. This reputational harm may be a significant deterrent (Ministry of Economic Development, 2000).

Several studies have investigated the deterrence effect of insider trading laws. Beny (2005) and Bris (2005) find that stronger laws are more effective in controlling the harm from insider trading (Beny, 2005) and its profitability (Bris, 2005). Frijns et al. (2008) look at the introduction of new insider trading laws in New Zealand in 2002 that increased the strength of the local rules, and find that those laws resulted in a significant reduction in information asymmetry in the market. While these studies do not specifically look at the effect of criminalization, they do show that the strength of insider trading laws can have a significant impact on markets.

While the seriousness of the threat imposed by criminal sanctions is not disputed, a number of studies have suggested that the increased burden of proof makes prosecution much less likely (Rakoff and Eaton, 1993; Engelen, 2006). Engelen (2006) argues that criminalization in Europe failed to achieve the goal of ensuring integrity in financial markets. Rakoff and Eaton (1993) highlight the difficulties in successfully prosecuting insiders criminally.

The importance of enforceability has recently been stressed by several studies. Bhattacharya and Daouk (2002) study the impact of the introduction and first enforcement of insider trading laws on the cost of capital. They find that the introduction of laws has no effect on the cost of capital, but that there is a significant reduction following the first enforcement. Bhattacharya and Daouk (2009) further find that those countries that enact laws but do not enforce them wind up with higher costs of capital than those that do not enact insider trading laws at all. Their study strongly suggests that enforceability is key in improving market 
conditions. However, no empirical study has yet examined the introduction of criminal sanctions and its impact on financial markets.

\subsection{The New Zealand Market}

The NZX is one of the smaller developed markets in the world (Bhattacharya and Daouk, 2002). The NZX currently lists around 160 companies. In addition, trading activity is relatively low, with around 41,598 trades, representing a combined value of NZ\$2.7 billion in the month of February 2008. The market capitalization for the total market is NZ\$ 37 billion. The NZX runs an electronic limit order book. New Zealand rates relatively high in most of the law and finance investor protection measures (La Porta et al., 1998; Djankov et al., 2008).

In 1999 and the early 2000s, the government focused strongly on regulatory factors that may have been undermining the local market. In particular, it was argued that the relatively lighthanded regulation in the past had resulted in a lack of investor confidence. One area that was highlighted in particular was insider trading, which was governed by a private enforcement regime. Since insider trading was explicitly included in securities legislation in 1988, no insiders have been successfully prosecuted and in several cases relatively high profile individuals avoided prosecution either through legal loopholes or by settling out of court. These cases included one where an insider, Eric Watson then CEO of the Blue Star Group, traded heavily prior to the announcement of an acquisition of McCollum Printer. Watson avoided prosecution due to a legal technicality and only surrendered his profit without additional penalties. In another case, Kerry Hoggard, then Chairman of Fletcher Challenge, purchased heavily before a major restructuring announcement. This case was settled out of court with financial penalties but other penalties relating to his ability to serve as a director were not imposed. As a result of the failure to convict insiders in these cases and with a number of other suspected instances of insider trading that were not prosecuted, the government introduced changes to the laws governing insider trading in the early 2000's.

The first change in the laws, introduced in 2002 and enacted in 2004, changed the private enforcement regime that had prevailed in New Zealand and tasked a local watchdog, the Securities Commission, with prosecuting insider trading. Soon after the enactment the Commission attempted prosecution of a number of insiders in Transrail, a local railroad 
company, who sold heavily prior to the announcement of poor financial performance, collectively avoiding $\$ 47$ million in losses. The prosecution wound up settling out of court, resulting in insiders repaying \$27 million without an admission of guilt. This case arguably undermined the deterrence of insider trading.

In earlier discussions on the 2002 laws, the introduction of criminal sanctions was mooted as a way of increasing deterrence. While there was little public support for criminalization, it was nevertheless introduced in a second round of amendments in 2006. These amendments, which came into effect in February 2008, added criminal sanctions of a maximum of 5 years in jail and/or a $\$ 300,000$ fine to the existing civil sanctions available. Since its enactment in 2008 , no attempts have been made by the public regulator to bring a prosecution against insiders.

\section{Methodology and Data}

\subsection{Measures of Informed Trading}

Evaluating the efficacy of insider trading laws is not straightforward because of the opaque nature of illegal insider trading. Given the potential penalties associated with being caught, insiders have strong incentives to hide their trading from the market and regulators. As such, obtaining a direct measure for the impact of insider trading is difficult. However, the consequence of insider trading is observable through several indirect measures. For example, based on the idea that normal (uninformed) investors must be compensated for the cost of insider trading, Bhattacharya and Daouk (2002) explore changes in the country-level cost of capital to proxy for the harm from insider trading. Beny (2005) looks at price synchronicity, the concentration of shareholdings and liquidity, while Bris (2005) looks at price run-ups and abnormal trading prior to takeover announcements. ${ }^{4}$

As an alternative approach to measuring the impact of insider trading, we turn to the market microstructure literature which focuses on the bid-ask spread and its components. The bid-

\footnotetext{
${ }^{4}$ While Bris (2005) uses a relatively direct measure of the prevalence of insider trading, it requires a significant amount of takeover activity before and after new legislation is introduced, and these restrictions are particularly problematic for a small stock exchange like New Zealand.
} 
ask spread is often referred to as the cost of trading or the market maker's compensation for these costs. These costs relate to operational costs, such as order processing or inventory costs, but also contain information asymmetry costs, i.e. the cost incurred when trading against a better informed counterparty. Insiders, when trading on their inside information are better informed counterparties, and any uninformed investor trading against them will lose in the transaction, a notion supported by a considerable wealth of literature detailing the profitability of insiders even when trading legally (see e.g., Jaffe 1974; Finnerty 1976; Seyhun 1986, 1998; Rozeff and Zaman 1988; and Lakonishok and Lee 2001 for the US, Baesel and Stein 1979 for Canada, Del Brio et al., 2002 for Spain, Etebari, et al., 2004 for New Zealand and Pope et al. 1990; Friederich et al., 2002 for the UK). To compensate for this risk of trading with a better informed counterparty, the bid-ask spread includes compensation to cover the cost of trading losses incurred. This compensation can be thought of as the market's expectation of the probability of trading against a better informed party and the average loss incurred. If insiders make up a sizeable proportion of the market, then this should be reflected in the spread. If a law reduces the prevalence of insider trading, then the proportion of informed traders in the market should decrease, and this should lead to a decrease in the spread. We explore the impact of criminalization of insider trading by considering four spread measures: the percentage spread; the effective spread; the price impact; and the proportion of information asymmetry based on Lin et al. (1995), and by considering the probability of informed trading (PIN) of Easley et al. (1996, 1997a, 1997b).

\subsubsection{The Percentage Spread}

The percentage spread is a measure of the overall cost of trading. It measures the spread as the percentage cost of a round trip trade if the trades were conducted at the quoted ask and bid prices. The percentage spread is measured as the difference between ask and bid prices divided by the midpoint of the quotes, i.e.

$$
P S_{i, t}=\frac{\left(A s k_{i, t}-B i d_{i, t}\right)}{\left(A s k_{i, t}+B i d_{i, t}\right) / 2}
$$

We employ intraday data to compute the percentage spread at the time of each trade, and compute the average percentage spread over all trades and companies in the sample. If the cost of trading reduces, i.e. the percentage spread decreases, it will encourage more trading, 
increasing liquidity in the market and the value of the firm (Amihud and Mendelson, 1986). As the goal of insider trading regulation is to reduce the harm from insider trading and ultimately promote market efficiency, a reduction in overall trading costs should be considered a good outcome.

\subsubsection{The Effective Spread}

The effective spread is similar to the percentage spread. However, the effective spread allows for trades to occur at different prices than the quoted bid and ask. This is particularly true in opaque markets where liquidity may not be fully reflected in quotes and opportunities exist to trade within the spread (Ready, 1999). But even in electronic markets traders can better existing quotes, or large orders can exhaust the shares available at the best price, resulting in execution prices that differ from quoted prices (Bessembinder and Venkataraman, 2010). In such cases, the effective spread is a more accurate measure of the actual trading costs. We measure the effective spread as the difference between the actual price at which a trade occurs and the midpoint of the prevailing quoted spread at the time of the trade, i.e.,

$$
E S_{i, t}=\frac{\left|P_{i, t}-\left(A s k_{i, t}+B i d_{i, t}\right) / 2\right|}{\left(A s k_{i, t}+B i d_{i, t}\right) / 2} .
$$

One issue with both the effective and quoted spreads is that they represent the total trading costs an investor incurs. As stated above, a reduction in these measures is positive for the market and is a desirable outcome. However, while these improvements could be due to a reduction in insider trading they may be related to other factors, such as an improvement in liquidity. As such, we employ two spread measures that focus specifically on the information asymmetry component of the spread.

\subsubsection{The Price Impact of Trades}

Several studies that focus on the decomposition of spreads have noted that it is possible to identify the different cost components based on the impact of trades on subsequent prices. Specifically, order processing and inventory holding costs lead to price reversals after the trade and only have a temporary impact on prices. On the other hand, information-driven trades present new information and cause permanent shifts in the underlying value of the security. This is because informed traders who have, say, positive news will place buy orders but not sell orders, resulting in extra demand to buy. Market makers and liquidity providers 
will observe this excess demand and adjust the bid and ask quotes to incorporate this information. As such, changes in the underlying value of the security between the time of the trade and some point in the near future reveal the market's assessment of the informational component of that trade.

Although the underlying value of a security is not directly observed, it is often proxied by the midpoint of the bid and ask quote (Bessembinder and Kaufman, 1997; Huang and Stoll, 1996, among others). As such, we measure the price impact of a trade as the absolute difference between the quoted midpoint $n$ periods after the trade and the quoted midpoint at the time of the trade divided by the midpoint at the time of the trade, i.e.

$$
P I_{i, t}=\left|\frac{M_{i, t+n}-M_{i, t}}{M_{i, t}}\right|,
$$

where $M_{i, t}$ is the quoted midpoint. The price impact measure has been shown to be relatively insensitive with respect to the choice of $n$ (Werner, 2003), although using a window that is too long may cause other events to affect the price impact measure. In line with Huang and Stoll (1996) we choose a 5-minute window. If we observe an increase (decrease) in information asymmetry as a result of the change in legislation we should see an increase (decrease) in the price impact of the trade.

\subsubsection{Proportion of Information Asymmetry}

Lin et al. (1995) offer a model for calculating the proportion of information asymmetry similar to the price impact measure. ${ }^{5}$ They argue that in response to an order, market specialists will revise the quotes they offer. They do this to attract order flow to balance their position and to ensure their costs are covered. If market participants trade according to this pattern, i.e. a buy followed by a sell and vice versa, then prices will only change temporarily. If we see order persistence (a buy followed by a buy), the impact on prices becomes

\footnotetext{
${ }^{5}$ Several other bid-ask spread decomposition models have been proposed by Madhavan et al. (1997), Huang and Stoll (1997) and Glosten and Harris (1988). All the approaches use similar reasoning although the specific methodologies do differ considerably in the method of estimation. The Lin et al. (1995) methodology however has been shown to estimate better than other models producing fewer implausible estimates (Van Ness et al. 2001).
} 
permanent. Lin et al. (1995) argue that the response of the midpoint to a trade at the bid or ask will reflect the degree of information asymmetry, i.e.

$$
\Delta m_{t+1}=\lambda z_{t}+e_{t+1}
$$

where $\Delta m_{t+1}$ is the change in the log of the quoted midpoint at time $t, z_{t}=p_{t}-m_{t}$ and $p_{t}$ is the $\log$ of the trade price at time $t$, and $\lambda$ is the information asymmetry component of the spread. If the introduction of criminal sanctions has increased (decreased) information asymmetry, we would expect to see an increase (decrease) in $\lambda$.

\subsubsection{The Probability of Informed Trading}

As an alternative to the spread-based models, we also consider the probability of informed trading (PIN). The PIN, proposed by Easley et al. (1996, 1997a, 1997b), is a widely used measure for the proportion of informed trading. The PIN looks at order imbalances between buyer- and seller-initiated trades to identify the number of information driven trades compared with the number of noise trades. More formally, the model assumes there are two types of traders, uninformed traders who trade for liquidity purposes and arrive in the market at a rate $\varepsilon$, and informed traders who trade on days when they have private information (the probability having private information on a given day is given by $\alpha$ ) and arrive at a rate $\mu$. The information held by informed traders can be either bad news (with probability $\delta$ ) or good news (with probability $1-\delta$ ). On a day when informed traders have a bad news signal, buy orders will occur at rate $\varepsilon$ but sell orders will occur at rate $\varepsilon+\mu$ creating an imbalance in the order flow. Likewise, on a good news day buy orders occur at rate $\varepsilon+\mu$ and sell orders at rate $\varepsilon$, while on no news days $(1-\alpha)$ both buys and sells occur at rate $\varepsilon$. The probability that a trade is executed by an informed trader is defined as

$$
P I N=\frac{\alpha \mu}{\alpha \mu+2 \varepsilon}
$$

If we assume that the order arrivals follow a Poisson process, then the coefficients in Equation (5) and the PIN can be estimated by maximum likelihood. For a detailed discussion 
on the PIN model and its estimation see Easley et al. (1996, 1997a, 1997b). An increase (decrease) in information asymmetry as a result of the change in sanctions will result in an increase (decrease) in PIN.

\subsection{Data}

To examine the impact of the introduction of the criminalization of insider trading on the market, intra-day price data are collected for New Zealand companies twelve months around the introduction of the law on 29 February 2008. We examine windows of three, six months and twelve months before and after the law's introduction. Intra-day prices are collected from the Thompson Reuters Tick History database available from $\operatorname{SIRCA}^{6}$ for all available companies that survived over the sample period. However, as we need high-frequency data to estimate the information asymmetry component of the spread, we require that companies must have at least five trades per day on average and have trades on at least 30 days for both the pre- and post-change periods to be included. This results in a final sample of 51 companies, or roughly one-third of the total number of companies listed on the NZX. For each of the measures discussed in Section 3.1, we compute two values, the pre-change and post-change value. Quoted and Effective Spreads, and Price Impacts are computed as the average of the per-trade values over the specific window. The Proportion of Information Asymmetry and the PIN are estimated based on all the available trades over the respective window.

Table 1 presents summary statistics. Over the entire sample period, we observe an average of 35.49 trades per day, although this is subject to considerable variation with the smallest company having just 5.82 and the largest company having 222.13 trades per day. Compared with studies on other exchanges these values are low. Madhaven et al. (1997) report an average of 95 trades per day for the NYSE and Ahn et al. (2002) report 296 trades per day for the Tokyo Stock Exchange. However, compared with an earlier study in New Zealand (Frijns et al., 2008), the mean trades per day has increased nearly twofold.

\footnotetext{
${ }^{6}$ Securities Industry Research Centre of Asia-Pacific.
} 


\section{INSERT TABLE 1 HERE}

We observe that the average dollar spread is about 6.4 cents per share, although the median is 4.96 cents per share. The minimum is less than one cent and the maximum 65 cents. ${ }^{7}$ The mean price is $\$ 4.36$ and the minimum and maximum of $\$ 0.17$ and $\$ 27.94$, respectively. When looking at the pre- and post-enactment subsamples, we note some preliminary evidence regarding the impact of the law changes. We observe that quoted spreads have increased in the post-change period for all three windows, and that average prices and volume traded have decreased with the sharpest declines in the twelve month window. These changes also affect the minimums and maximums. This may provide some preliminary evidence that criminalization has harmed the market.

\section{Results}

To study whether the criminalization of insider trading in New Zealand has had a positive or negative impact on the market, we examine a range of bid-ask spread based measures that incorporate or measure the information asymmetry cost component of the spreads. In addition, we consider the PIN before and after the enactment of the new legislation.

\subsection{Univariate Analysis}

Panel A of Table 2 presents the results for the percentage spread. The percentage spread is a measure for the total cost of trading. Given that the goal of effective legislation should be to reduce overall market frictions, it is appropriate to look at the effect on percentage spreads. If the introduction of criminal sanctions has been positive (negative) for the market, we expect the percentage spreads to decrease (increase).

For the full sample, we find that the average percentage spread is $2.22 \%$. This is pushed up by a few companies that have larger percentage spreads as the median is slightly lower at $1.92 \%$. The percentage spreads are, however, larger than those reported by Frijns et al. (2008) $(1.18 \%)$ in their study on the NZX or in studies of other markets, which typically find

\footnotetext{
${ }^{7}$ Note that the minimum tick size is $\$ 0.01$.
} 
percentage spreads of less than 1\% (Madhaven et al., 1997; Ahn et al., 2002). Most likely, this is a result of the minimum tick size of 1c per share and the low prices, as shown in Table 1.

When we examine the differences between the pre- and post-enactment periods, we observe a marked increase in the percentage spreads for all three windows, with increases of $0.3 \%$, $0.6 \%$ and $1 \%$ for the three-, six- and twelve-month samples, respectively. These gradual increases suggest that the law has taken some time to be fully reflected in the spreads. We observe similar increases in the medians and the tails of the sample. We conduct a t-test on the differences between the means before and after the enactment and find strong significance at the $1 \%$ level for all windows. In addition, we employ Mann-Whitney $U$ tests to assess the significance of the differences in medians, which shows a significant increase of $0.54 \%$ and $0.73 \%$ in the six- and twelve-month windows. Finally, we observe that as the windows get longer, the number of firms with larger percentage spreads following the introduction of the law increase. For the three-month window two-thirds of the firms have a post-change increase in percentage spread (34 out of 51) which rises to $80 \%$ in the six-month window (43) and $90 \%$ in the twelve-month window (46). These results are strongly supportive of an increase in quoted spreads following the introduction of criminalization.

\section{INSERT TABLE 2 HERE}

Panel B of Table 2 examines the effective spreads in the pre- and post-change periods. We again conclude there has been a deterioration in the trading costs. Average effective spreads increase significantly by $0.12 \%, 0.28 \%$ and $0.33 \%$ for the three-, six- and twelve-month samples, respectively. We also observe that the increase is present throughout the crosssection of stocks with around $60 \%$ of companies seeing increases in the three and six-month windows and all except one in the twelve-month window. The twelve-month window also shows a significant increase in the median effective spread. These results further support the finding that there has been a worsening in the market around the introduction of criminal sanctions. 
The results for overall trading costs suggest that there has been an increase in spreads around the time of the introduction of the criminal sanctions. To determine whether this is attributable to insider trading, we employ two measures to identify the information asymmetry component of the spread: the price impact of trades, and the Lin et al. (1995) measure.

Panel $\mathrm{C}$ of Table 2 shows the results for the price impact of trades. On average, there is a permanent price change following a trade of approximately $0.45 \%$. We observe a significant change in the price impact following the introduction of the new law, with a significant increase of $0.04 \%$ in the three-month sample, $0.07 \%$ for the six-month sample and $0.37 \%$ for the twelve-month sample. We also notice that the increase is omnipresent with increases in the medians, first and third quartile values for all the windows. Finally, the number of companies with increases is greater than the number of companies with decreases, nearly two-thirds for the three-month window, over $80 \%$ of companies for the six-month window and virtually all companies in the twelve-month sample.

Our second information asymmetry measure is the proportion of information asymmetry of Lin et al. (1995). We conduct Wald tests on the difference in regression coefficients estimated for the pre- and post-change periods to see the number of significant increases and decreases and also a Chow test to see if there is a structural break around the time of the introduction of the new laws. If the law resulted in changes to the attitude of market participants about the prevalence and harm of insider trading, we expect to see changes in the size of the information asymmetry component of the spread.

Panel D of Table 2 shows that, on average, $26 \%$ of the spread is made up of information asymmetry costs. As with the measures previously discussed, we see an increase in the average, median and quartile values for the estimated proportion of information asymmetry. We observe a nearly $2 \%$ increase in the information asymmetry component for the threemonth window, just over $3 \%$ for the six-month window and $12 \%$ for the twelve-month window. In addition, a quarter of the sample has a significant increase in the proportion of information asymmetry in the three-month window, over one-third for the six-month window, and two-thirds of the sample companies for the twelve-month window. By contrast, the number of firms with significant decreases is smaller than the number with increases for 
the three-month sample and gets smaller with the longer windows. Finally, we observe a structural break for over $80 \%$ of the firms in all windows suggesting that the law change could be responsible for the changes observed.

An alternative way of examining the impact of the introduction of criminal sanctions is to employ the PIN model of Easley et al. (1996, 1997a, 1997b). If criminalization has decreased insider participation in the market, we would expect to see a reduction in the PIN.

Panel E of Table 2 presents the results for the PIN. The full sample shows that over this time period the average PIN was about $23.2 \%$ suggesting that nearly a quarter of all trades were informed. We also see that the standard deviation is relatively small at $6.66 \%$ suggesting a relatively narrow distribution. When we separate the results into the pre- and post-change groups we observe a marked increase in the PIN value across the entire range for the two shorter windows. For the six-month window there is a significant increase of $3.2 \%$ with a similar increase in the median. Likewise for the three-month window there is a significant increase of $2.5 \%$ with a slightly smaller increase in the median. However, the twelve-month window presents a slightly different picture with no significant changes in either the average or the median. We also observe that only just under half of the firms had an increase in the PIN.

\subsection{Trading Activity and Information Asymmetry Sorts}

As discussed by Easley et al. (1996), Gregory et al. (1997) and Friederich et al. (2002), not all companies are affected equally by insider trading. More liquid companies with more attention from analysts and the media tend to have fewer opportunities for insider trading as prices remain close to fundamentals and so are less affected. Frijns et al. (2008) show that this difference in prevalence also has an impact on the way legislation affects companies with less trading activity and those with greater pre-enactment information asymmetry. In line with this, we sort companies on the basis of total number of pre-enactment trades observed and also the pre-change information asymmetry estimates from the Lin et al. (1995) model and test whether the law changes have a greater effect on those companies most affected by insider trading. We take the twenty highest and lowest companies for each sort and recalculate the average values for each of the measures employed. In addition, we test for significant differences in the means. 
Panel A of Table 3 shows the results for each of the five measures when we sort on the prechange number of trades. The results strongly support the idea that the changes in insider trading laws initially had a disproportionate effect on stocks with different levels of liquidity. When we examine the low trade group over the three- and six-month windows, we see significant differences in the pre- and post-enactment periods suggesting that illiquid stocks are adversely affected by the introduction of the new law. For the liquid stocks, we find no significant difference between pre- and post-change period with the exception of the PIN. The twelve-month sample, by contrast, shows significant differences for both low and high trade groups for all five measures, although the low trade PIN group has the wrong sign.

\section{INSERT TABLE 3 HERE}

Panel B repeats the sorting but uses the pre-change information asymmetry of Lin et al. (1995). Overall, the results indicate that there has been a worsening in the cost of trading as a result of the introduction of the SMAA. However, we obtain significance for both low and high information asymmetry firms for four of the measures. We also find strong significance for all measures except of the PIN in the twelve-month sample.

\subsection{Multivariate Analysis}

The results of the means tests suggest that the introduction of criminal sanctions for insider trading has not been effective in deterring insiders. All of our measures show evidence of a significant worsening following the introduction of the criminal sanctions. One possibility, however, is that the worsening in spread measures and the PIN is the result of other events that have led to a deterioration of the market as a whole. We address this issue by employing a difference-in-difference approach to control for both market-wide effects and other factors affecting spreads and the PIN. ${ }^{8,9}$

The difference-in-difference approach involves comparing a treatment group which has been exposed to a change (in this case the introduction of criminal sanctions) with a control group

\footnotetext{
${ }^{8}$ We would like to thank an anonymous referee for this valuable suggestion.

${ }^{9}$ See Roberts and Whited (2011) for an excellent treatment on difference-in-difference estimation.
} 
that has not been exposed. As our event is a New Zealand-wide event, we employ a control group comprised of firms from the Australian Stock Exchange (ASX). The ASX represents the closest market to the NZX in terms of regulatory framework and with regards to the impact of the Global Financial Crisis. ${ }^{10}$ To select our control sample, we employ propensity scores to find the closest possible firm to our treatment firm. Firms have to come from the same industry (based on four digit SIC codes) and are matched based on the lowest propensity score calculated using market capitalization, book to market ratio and price for the twelve months prior to the change in law. We choose these factors as the basis of our matching criteria as they are related to the size of spreads in the market. Firms for which the same liquidity requirements imposed on our treatment group are not met, namely five trades per day and a minimum of thirty days of trading in both the pre- and post-change windows, are discarded and the next nearest match is taken instead. The control group consists of 43 Australian firms that represent the same industry and the closest match on the other factors to our treatment firms.

To determine the impact of the change in the legislation on our information asymmetry measures, we run a difference-in-difference regression in its first difference form, i.e.

$$
\Delta I A_{i}=\alpha+\beta D_{i}^{N Z X}+\sum_{k} \gamma_{k} \Delta \text { Control }_{k i}+\varepsilon_{i}
$$

where $\triangle I A_{i}$ is the difference in our microstructure measures between the pre- and post-change windows. We include a dummy variable, $D^{N Z X}$, which is equal to one if the firm in question is an NZX firm. Our variable of interest, $\beta$, can be viewed as the coefficient of the difference between the pre- and post-change difference between the New Zealand firms in the treatment group and the ASX firms in the control sample. A positive coefficient for $\beta$ represents a worsening in the measure and would be supportive of the results presented in Table 2.

In addition to controlling for market-wide events, we include other well known factors that affect spreads. Specifically, we control for the difference in the natural logarithm of the

\footnotetext{
${ }^{10}$ As the crisis was largely driven by problems in the banking system, and New Zealand banks are predominantly subsidiaries of Australian banks there was a similar level of impact from the crisis. Further, both markets have been relatively insulated from the global recession by their reliance on commodity based exports.
} 
average market capitalization before and after the change $(\triangle M V)$; the difference in the average market to book ratios (to control for growth opportunities) $(\triangle M B)$; the difference in the natural logarithm of the average number of trades per day $(\Delta T / D)$; and the difference in volatility (variance) of returns over the pre- and post-change windows ( $\triangle$ Vola). Many of these variables have been widely employed in the literature to control for spreads. However, as we estimate the difference-in-difference model in its first difference form, we do not expect many of these variables to have significant coefficients in our regressions. If we do find significance in these coefficients it implies a change between the treated and control samples that is not related to the change in legislation.

\section{INSERT TABLE 4 HERE}

Panel A of Table 4 presents the regression coefficients for the twelve-month window and strongly suggests that criminalization has had a negative impact on the market. For three of the four spread measures and the PIN we observe a strongly significant and positive coefficient for $D^{N Z X}$. Only the coefficient for the effective spread is insignificant. The results indicate that after controlling for market-wide trends and other factors our information asymmetry measures are larger after the change in the law than before. We also observe significant increases in all the spread measures for the constant. This represents a general increase in information asymmetry measures in both markets between the pre- and postchange periods. None of the other controls are consistently significant as expected.

Panel B of Table 4 presents the same analysis for the six-month window. The results are broadly consistent with the results for the twelve-month window. We observe significant positive coefficients for effective spreads, the proportion of information asymmetry and the PIN. We further note significant increases in three of our measures for the constant. The other control variables are not consistently significant.

Panel $\mathrm{C}$ of Table 4 presents the three-month window results. The results for this window are weaker than the previous two windows, suggesting that the implications of the law change may have taken some time to become fully reflected in the market. The immediate market reaction to the introduction however shows significance for the percentage spread and the 
proportion of information asymmetry. We also observe little significance in the constant or in any of the other controls.

As we noted earlier, it is likely that not all firms are affected equally by this law change. Firms that are more prone to insider trading (less liquid firms with high information asymmetry) should be affected to a greater extent if this law change has had the negative effect on market efficiency our results suggest. As with the difference in means tests where we sorted firms into those most likely to be affected, we introduce two dummies separately to account for those firms most likely to be affected by the law change and estimate the regression

$$
\Delta I A_{i}=\alpha+\beta D_{i}^{N Z X}+\delta D_{i}^{L i q}+\sum_{k} \gamma_{k} \Delta \text { Control }_{k i}+\varepsilon_{i},
$$

where $D_{i}^{L i q}$ is a dummy variable equal to 1 if the firm is a low trade or high information asymmetry firm in the NZX market, and $\delta$ measures the excess impact of the law change for low trade or high information asymmetry firms over all firms in the NZX sample.

\section{INSERT TABLE 5 HERE}

Panel A of Table 5 presents the results for Equation (5) where two dummy variables for the most affected firms for the twelve-month window are included (we estimate this in separate regressions). All controls reported in Table 4 are included in these regressions, but are not reported for the sake of brevity. The two variables that we include separately are Low Trade, which equals 1 for the low trade group of NZX firms in the first five columns, and High IA, a dummy that equals 1 for high pre-change information asymmetry in the second five columns. The results support our earlier findings that the law change affects both low trade and high information asymmetry firms more than more liquid and firms with lower information asymmetry. We see positive significant coefficients on the dummies for the percentage and effective spreads and the price impact measure. LSB and PIN are significantly negative, consistent with the earlier findings in Table 3. The results further show that the coefficient on $D^{N Z X}$ remains significant and positive suggesting that the results in Table 4 are not only driven by a part of the sample, but that all firms are affected. 
Panel B of Table 5 presents the same analysis conducted on the six-month window. We find similar results, with percentage and effective spreads significant for both sorts and the price impact and $L S B$ significant for the low trade and high IA groups respectively. We again observe strong significance for $D^{N Z X}$, supporting the hypothesis that the law changes affected all firms.

The results in Panel $\mathrm{C}$ of Table 5 are also supportive of the negative consequences of the changes. The low trade coefficient is significant and positive for four measures, while high IA is positive for three measures. We further find support for the effects being market wide with the exception of a few instances.

Overall our results provide strong evidence that the criminal sanctions introduced to New Zealand in February 2008 have had the opposite effect to that intended by the policy makers. Rather than improve the efficiency of the market by deterring insiders it would appear that the market believes enforcement and so deterrence to now be weaker. As a result we see, in both the difference in means and in a multivariate setting employing differences-in-difference regressions, that spreads have widened as a result of an increase in the cost of information asymmetry and that informed trading has increased. Therefore, criminal sanctions do not appear to have been effective in controlling insiders.

\section{Conclusion}

Criminal sanctions for insider trading laws have been used widely around the globe by regulators in an effort to deter insider trading. While some commentators and academics have questioned the efficacy of these sanctions, there has been little empirical evidence regarding the benefits or costs of these sanctions. This study uses a unique opportunity to examine the introduction of criminal sanctions within a developed market, New Zealand.

We collect data on companies for three windows, twelve, six and three months prior to and following the $29^{\text {th }}$ February 2008, the date that the new rules came into effect. Using an event study-type methodology, we explore changes in four spread-based measures that incorporate 
the cost of information asymmetry; namely the percentage spread, effective spread, price impact of trades and Lin et al.'s (1995) proportion of information asymmetry measure, in addition to the PIN model (Easley et al., 1996, 1997a, 1997b). The results for all five measures show that the introduction of criminal sanctions in New Zealand for insider trading offences has resulted in a statistically significant increase in the cost of trading and the degree of information asymmetry. These results are also economically significant, as the effective spread has increased by an average of $63 \%$ in the period 12 months before the enactment and 12 months after. Additional robustness tests including sorting on trading liquidity and prechange information asymmetry and a difference-in-difference approach confirm these findings. Overall, our findings suggest that the introduction of criminal sanctions has not been successful in reducing the impact of insider trading in New Zealand. These findings raise questions regarding the effectiveness of criminal sanctions, especially given their increasing acceptance around the world. 


\section{References}

Ahn, H. J., Cai, J., Hamao, Y., \& Ho, R. (2002). The Components of the Bid-Ask Spread in a Limit-Order Market: Evidence from the Tokyo Stock Exchange. Journal of Empirical Finance, 9, 399-430.

Amihud, Y., \& Mendelson, H. (1986). Asset pricing and the bid-ask spread. Journal of Financial Economics, 17, 223-249.

Baesel, J., \& Stein, G. (1979). The Value of Information: Inferences from the Profitability of Insider Trading. Journal of Financial and Quantitative Analysis, 14, 553-571.

Becker, G. (1968). Crime and Punishment: An Economic Approach. The Journal of Political Economy, 76, 169-217.

Beny, L. (2004). A comparative empirical investigation of agency and market theories of insider trading. John M. Olin Center for Law and Economics Working Paper.

Beny, L. (2005). Do Insider Trading Laws Matter? Some Preliminary Comparative Evidence. American Law and Economics Review, 7, 144-183.

Bessembinder, H. \& Kaufman, H. (1997). A Comparison of Trade Execution Costs for NYSE and NASDAQ-listed Stocks. Journal of Financial and Quantitative Analysis, 32, 287310.

Bessembinder, H. \& Venkataraman, K. (2010). Bid-Ask Spreads: Measuring Execution Costs in Financial Markets. Encyclopaedia of Quantitative Finance. Wiley.

Bhattacharya, U., \& Daouk, H. (2002). The World Price of Insider Trading. Journal of Finance, 57, 75-108.

Bhattacharya , U., \& Daouk, H. (2009). When No Law is Better than a Good Law. Review of Finance, 13, 577-627. 
Bris, A. (2005). Do Insider Trading Laws Work? European Financial Management, 11, 267312.

D’Aliosio, T. "Insider Trading and Market Manipulation". A speech to the Supreme Court of Victoria Law Conference, Melbourne. 13 August 2010.

Del Brio, E., Miguel, A., \& Perote, J. (2002). An Investigation of Insider Trading Profits in the Spanish Stock Market. Quarterly Review of Economics and Finance, 42, 73-94.

Djankov, S., La Porta, R., Lopez-de-Silanes, F. \& Shleifer, A. (2006). The Law and Economics of Self-Dealing. Journal of Financial Economics, 88, 430-465.

Duffy, M. (2009). Insider Trading : Addressing the continuing problems of proof. Australian Journal of Corporate Law, 23, 149-177.

Easterbrook, F. (1985). Insider Trading as an Agency Problem. In Pratt, J., and Zeckhauser, R. eds. Principles and Agents : The structure of Business 81.

Easley, D., Kiefer, N. \& O'Hara, M. (1997a). The Information Content of the Trading Process. Journal of Empirical Finance, 4, 159-185.

Easley, D., Kiefer, N. \& O’Hara, M. (1997b). One day in the Life of a Very Common Stock. Review of Financial Studies, 10, 805-835.

Easley, D., Kiefer, N., O’Hara, M., \& Paperman, J. (1996). Liquidity, information, and infrequently traded stocks. Journal of Finance 51, 1405-36.

Engelen, P. (2006). Difficulties in the criminal prosecution of insider trading - A clinical study of the Bekaert case. European Journal of Law and Economics, 22, 121-141.

Etebari, A., Tourani-Rad, A., \& Gilbert, A. (2004). Disclosure Regulation and the Profitability of Insider Trading: Evidence from New Zealand. Pacific-Basin Finance 
Journal, 12, 479-509.

Financial Times. (1998) Louden Clear. May 20. Financial Times (London)

Finnerty, J. (1976). Insiders and Market Efficiency. Journal of Finance, 31, 1141-1148.

Friederich, S., Gregory, A., Matako, J., \& Tonks, I. (2002). Detecting returns around the trades of corporate insiders in the London Stock Exchange. European Financial Management 8, 7-30.

Frijns, B., Gilbert, A., \& Tourani-Rad, A. (2008). Insider Trading, Regulation and the Components of the Bid-Ask Spread. Journal of Financial Research, 31, 225-246.

Frijns, B., Gilbert, A., \& Tourani-Rad, A. (2010). Elements of Effective Insider Trading Laws. Working Paper.

Gilbert, A., Tourani-Rad, A., \& Wisniewski, T. (2007). Insiders and the Law: The Impact of Regulatory Change on Insiders Trading. Management International Review 5, 745765.

Glosten, H. \& Harris, L. (1988). Estimating the components of the bid-ask spread. Journal of Financial Economics 21, 123-42.

Gregory, A., Matatko, J., \& Tonks, I. (1997). Detecting information from directors' trades: Signal definitionand variable size effects. Journal of Business Finance and Accounting 24, 309-42.

Huang, R., \& Stoll, H. (1996). Dealer versus auction markets : A paired comparision of execution costs on NASDAQ and NYSE. Journal of Financial Economics, 41, 313357.

Huang, R., \& Stoll, H. (1997) The components of the bid-ask spread: A general approach. Review of Financial Studies 10. 995-1034. 
Jaffe, J. (1974). Special Information and Insider Trading. Journal of Business, 47, 410-428.

Joo, T. (2007). Legislation and Legitimation: Congress and Insider Trading in the 1980s. Indiana Law Journal 82, 575-608

La Porta, R., Lopez-de-Silanes, F., Schleifer, A., \& Vishny, R. (1998). Law and Finance. Journal of Political Economy, 52, 1113-1155.

Lakonishok, J., \& Lee, I. (2001). Are Insiders Trades Informative. The Review of Financial Studies, 14, 79-111.

Lin, J., Sanger, G., \& Booth, G. (1995). Trade size and components of the Bid Ask Spread. Review of Financial Studies, 8, 1153-1183.

Madhavan, A., Richardson, M., \& Roomans, M. (1997). Why Do Security Prices Change? A Transaction-Level Analysis of NYSE Stocks. The Review of Financial Studies, 10(4), 1035-1064.

Ministry of Economic Development. (2000). Insider Trading Discussion Document. Available at http://www.med.govt.nz/templates/MultipageDocumentTOC 7574.aspx

Newkirk, T. \& Robertson, M. "Insider Trading - A U.S. Perspective". Remarks to the $16^{\text {th }}$ International Symposium on Economic Crime, Jesus College, Cambridge. Available at: www.sec.gov/news/speech/speecharchive/1998/spch221.htm.

Pope, P., Morris, R., \& Peel, D. (1990). Insider Trading: Some Evidence on Market Efficiency and Directors Share Dealings in Great Britian. Journal of Business, Finance and Accounting, 17, 359-380.

Rakoff, J. \& Eaton, J. (1993). How Effective is US Enforcement in Deterring Insider Trading? Journal of Financial Crime 3,283-287. 
Ready, M. (1999). The specialist's discretion: Stopped orders and price improvement. Review of Financial Studies 12, 1075-1112.

Roberts, M. \& Whited, T. (2011). Endogeneity in Empirical Corporate Finance. Bradley Policy Research Center Working Paper FRI1-29. Available at http://ssrn.com/abstract=1748604

Rozeff, M., \& Zaman, M. (1988). Market Efficiency and Insider Trading: New Evidence. Journal of Business, 61, 25-43.

Seyhun, N. (1986). Insider Profits, Costs of Trading and Market Efficiency. Journal of Financial Economics, 16, 189-212.

Seyhun, N. (1998). Investment Intelligence from Insider Trading. Cambridge, MA: MIT Press.

US Securities and Exchange Commission. SEC v. Martha Stewart and Peter Bacanovi. Litigation Release $\quad$ No. $19794 . \quad$ Available at http://www.sec.gov/litigation/litreleases/2006/lr19794.htm

Van Ness, B., Van Ness, R., \& Warr, R. (2001). How well do adverse selection components measure adverse selection? Financial Management 30, 77-98.

Werner, I. (2003). NYSE order flow, spreads, and information. Journal of Financial Markets, 6, 309-335. 
Table 1. Descriptive Statistics

\begin{tabular}{|c|c|c|c|c|c|c|c|}
\hline & \multirow[b]{2}{*}{ Full } & \multicolumn{2}{|c|}{ Twelve-Month Window } & \multicolumn{2}{|c|}{ Six Month Window } & \multicolumn{2}{|c|}{ "Three Month Window } \\
\hline & & Pre & Post & Pre & Post & Pre & Post \\
\hline \multicolumn{8}{|c|}{ Number of Trades } \\
\hline Average & 17767.98 & 9144.98 & 8589.51 & 4473.84 & 2076.22 & 2043.90 & 4391.33 \\
\hline Std Dev & 21355.59 & 10008.29 & 11562.56 & 5063.07 & 2424.72 & 2530.49 & 5976.66 \\
\hline Min & 2634 & 1542 & 894 & 721 & 247 & 275 & 529 \\
\hline $\operatorname{Max}$ & 111510 & 50085 & 61248 & 24435 & 11576 & 13067 & 31305 \\
\hline \multicolumn{8}{|c|}{ Trades Per Day } \\
\hline Average & 35.49 & 36.34 & 34.62 & 35.86 & 34.68 & 34.12 & 35.20 \\
\hline Std Dev & 42.48 & 39.68 & 46.37 & 40.46 & 40.36 & 42.14 & 47.77 \\
\hline Min & 5.82 & 6.56 & 4.24 & 6.15 & 5.04 & 5.00 & 4.64 \\
\hline Max & 222.13 & 198.75 & 245.98 & 195.48 & 192.93 & 217.78 & 250.44 \\
\hline \multicolumn{8}{|c|}{ Average Volume } \\
\hline Average & 12273.5 & 12291.75 & 12358.17 & 12859.12 & 14449.75 & 11866.97 & 12136.77 \\
\hline Std Dev & 10585.04 & 11880.16 & 11344.13 & 14426.15 & 22765.38 & 11143.58 & 10913.52 \\
\hline Min & 2356.6 & 2321.90 & 1679.10 & 1783.33 & 1712.70 & 1604.56 & 1799.18 \\
\hline $\operatorname{Max}$ & 47648 & 59369.00 & 62525.00 & 90173.25 & 158344.02 & 56156.48 & 50850.20 \\
\hline \multicolumn{8}{|c|}{ Average Quoted Spread } \\
\hline Average & 0.0642 & 0.0627 & 0.0662 & 0.0747 & 0.0735 & 0.0802 & 0.0840 \\
\hline Std Dev & 0.1238 & 0.1259 & 0.1313 & 0.0952 & 0.0836 & 0.0993 & 0.1242 \\
\hline Min & 0.0055 & 0.0054 & 0.0055 & 0.0098 & 0.0107 & 0.0091 & 0.0088 \\
\hline $\operatorname{Max}$ & 0.6564 & 0.7753 & 0.7660 & 0.5083 & 0.4582 & 0.6471 & 0.8614 \\
\hline \multicolumn{8}{|c|}{ Average Price (in NZ\$) } \\
\hline Average & 4.36 & 4.61 & 3.49 & 4.91 & 4.53 & 4.19 & 4.05 \\
\hline Std Dev & 5.14 & 0.18 & 0.14 & 0.53 & 0.25 & 0.13 & 0.20 \\
\hline Min & 27.94 & 32.66 & 25.08 & 0.18 & 0.17 & 0.16 & 0.15 \\
\hline Max & 4.36 & 4.61 & 3.49 & 32.25 & 29.99 & 28.19 & 27.54 \\
\hline
\end{tabular}


Table 2. Univariate Analysis of Information Asymmetry Measures

\begin{tabular}{|c|c|c|c|c|c|c|c|}
\hline & & \multicolumn{2}{|c|}{ One Year Window } & \multicolumn{2}{|c|}{ Six Month Window } & \multicolumn{2}{|c|}{ Three Month Window } \\
\hline & Full Sample & Pre Enact & Post Enact & Pre Enact & Post Enact & Pre Enact & Post Enact \\
\hline \multicolumn{8}{|c|}{ Panel A: Quoted Spreads } \\
\hline Average & 0.0223 & 0.0208 & 0.0238 & 0.0186 & 0.0246 & 0.0211 & 0.0311 \\
\hline Median & 0.0192 & 0.0176 & 0.0207 & 0.0153 & 0.0207 & 0.0180 & 0.0254 \\
\hline Std Dev & 0.0124 & 0.0117 & 0.0131 & 0.0102 & 0.0133 & 0.0119 & 0.0184 \\
\hline First Quartile & 0.0135 & 0.0123 & 0.0146 & 0.0113 & 0.0150 & 0.0133 & 0.0167 \\
\hline Third Quartile & 0.0290 & 0.0272 & 0.0307 & 0.0241 & 0.0341 & 0.0253 & 0.0424 \\
\hline Average Diff & & & $0.0029 * * *$ & & $0.0057 * * *$ & & $.0100 * * *$ \\
\hline T-Stat & & & 3.17 & & 5.71 & & 6.87 \\
\hline Median Diff & & & 0.0031 & & $0.0054^{* *}$ & & $.0073 * * *$ \\
\hline Number Increases & & & 34 & & 43 & & 46 \\
\hline \multicolumn{8}{|c|}{ Panel B: Effective Spreads } \\
\hline Average & 0.0194 & 0.0188 & 0.0200 & 0.0175 & 0.0203 & 0.0052 & 0.0085 \\
\hline Median & 0.0125 & 0.0129 & 0.0120 & 0.0115 & 0.0157 & 0.0046 & 0.0069 \\
\hline Std Dev & 0.0166 & 0.0158 & 0.0173 & 0.0148 & 0.0181 & 0.0027 & 0.0047 \\
\hline First Quartile & 0.0079 & 0.0085 & 0.0073 & 0.0081 & 0.0075 & 0.0034 & 0.0051 \\
\hline Third Quartile & 0.0276 & 0.0257 & 0.0295 & 0.0234 & 0.0296 & 0.0070 & 0.0115 \\
\hline Average Diff & & & $0.0012 *$ & & $0.0028 * * *$ & & $.0033 * * *$ \\
\hline T-Stat & & & 1.72 & & 3.06 & & 8.27 \\
\hline Median Diff & & & -0.001 & & 0.0042 & & $.0023 * * *$ \\
\hline Number Increases & & & 29 & & 30 & & 50 \\
\hline \multicolumn{8}{|c|}{ Panel C: Price Impacts } \\
\hline Average & 0.0045 & 0.0044 & 0.0046 & 0.0040 & 0.0047 & 0.0062 & 0.0099 \\
\hline Median & 0.0040 & 0.0039 & 0.0041 & 0.0034 & 0.0042 & 0.0056 & 0.0087 \\
\hline Std Dev & 0.0020 & 0.0018 & 0.0022 & 0.0017 & 0.0020 & 0.0025 & 0.0044 \\
\hline First Quartile & 0.0031 & 0.0031 & 0.0031 & 0.0027 & 0.0031 & 0.0043 & 0.0063 \\
\hline Third Quartile & 0.0059 & 0.0054 & 0.0063 & 0.0050 & 0.0063 & 0.0072 & 0.0125 \\
\hline Average Diff & & & $0.0004 * *$ & & $0.0008 * * *$ & & $.0037 * * *$ \\
\hline T-Stat & & & 2.06 & & 5.46 & & 9.18 \\
\hline Median Diff & & & 0.0002 & & $0.0008 * *$ & & $.0031 * * *$ \\
\hline Number Increases & & & 33 & & 44 & & 50 \\
\hline \multicolumn{8}{|c|}{ Panel D: Proportion of Information Asymmetry } \\
\hline Average & 0.2647 & 0.2557 & 0.2736 & 0.2449 & 0.2753 & 0.2055 & 0.3213 \\
\hline Median & 0.2582 & 0.2501 & 0.2662 & 0.2305 & 0.2816 & 0.1975 & 0.2794 \\
\hline Std Dev & 0.1052 & 0.0969 & 0.1135 & 0.0871 & 0.0998 & 0.0795 & 0.1633 \\
\hline First Quartile & 0.1874 & 0.1850 & 0.1898 & 0.1830 & 0.2007 & 0.1352 & 0.2122 \\
\hline Third Quartile & 0.3289 & 0.3130 & 0.3447 & 0.3186 & 0.3360 & 0.2706 & 0.3798 \\
\hline \# Sig. Increase & & $25.4 \%$ & 18 & $37.3 \%$ & 19 & $66.7 \%$ & 34 \\
\hline \# Sig. Decrease & & $15.7 \%$ & 12 & $9.8 \%$ & 5 & $3.9 \%$ & 2 \\
\hline Structural Breaks & & $88.2 \%$ & 45 & $84.3 \%$ & 43 & $88.2 \%$ & 45 \\
\hline \multicolumn{8}{|c|}{ Panel E: Probability of Informed Trading } \\
\hline Average & 0.2319 & 0.2194 & 0.2444 & 0.2044 & 0.2364 & 0.2255 & 0.2194 \\
\hline Median & 0.2246 & 0.2143 & 0.2349 & 0.1914 & 0.2277 & 0.2040 & 0.2156 \\
\hline Std Dev & 0.0671 & 0.0604 & 0.0738 & 0.0641 & 0.0621 & 0.0660 & 0.0518 \\
\hline First Quartile & 0.1849 & 0.1805 & 0.1892 & 0.1648 & 0.1862 & 0.1749 & 0.1790 \\
\hline Third Quartile & 0.2810 & 0.2621 & 0.2998 & 0.2399 & 0.2808 & 0.2666 & 0.2578 \\
\hline Average Diff & & & $0.0249 * * *$ & & $0.0319 * * *$ & & .0054 \\
\hline T-Stat & & & 2.9568 & & 3.9652 & & .65 \\
\hline Median Diff & & & 0.0206 & & $0.0363 * *$ & & .0116 \\
\hline Number Increases & & & 31 & & 34 & & 25 \\
\hline
\end{tabular}

Note: Full Sample covers the period 28 February 2007 until February 28 2009. Percentage Spreads are calculated as the cross-sectional average of the bid-ask spread divided by the midpoint of the spread. Effective Spreads arere calculated as the cross-sectional average of the transaction price less the midpoint of the spread divided by the midpoint of the spread. Price Impacts are calculated as the cross-sectional average of the midpoint of the spread 5 minutes after a trade minus the midpoint of the spread at the time of the trade divided by the midpoint of the spread at the time of the trade. Significance for these measures is assessed using a matched-pairs t-test. Proportion of Information Asymmetry is computed using the Lin et al. (1995) decomposition model. This is calculated as the cross-sectional average of $\lambda$ in the regression formula $\Delta m_{t+1}=\lambda z_{t}+e_{t+1}$ where, $\Delta m_{t}$ is the change in the log of the quoted midpoint at time $t$, and $z_{t}=p_{t}-m_{t}$, where $p_{t}$ is the log of the trade price at time $t$. Significant increase/decrease is calculated using a Wald Test. The Probability of Informed Trading is computed following Easley et al. $(1996,1997 \mathrm{a}, 1997 \mathrm{~b})$ and significance is assessed using a paired t-test. Significance at the $10 \%, 5 \%$, and $1 \%$ level is indicated by $*{ }^{*}$, and $* * *$, respectively. 
Table 3. Trading Activity and Information Asymmetry Sorts

\begin{tabular}{|c|c|c|c|c|c|c|c|c|c|}
\hline & \multicolumn{3}{|c|}{ One Year Window } & \multicolumn{3}{|c|}{ Six Month Window } & \multicolumn{3}{|c|}{ Three Month Window } \\
\hline & Pre & Post & Diff & Pre & Post & Diff & Pre & Post & Diff \\
\hline \multicolumn{10}{|c|}{ Panel A: Sort by Pre-Change Trading Activity } \\
\hline \multicolumn{10}{|l|}{ Quoted Spread } \\
\hline Low Trades & 0.0294 & 0.0410 & $0.0117 * * *$ & 0.0279 & 0.0347 & $0.0077 * * *$ & 0.310 & 0.0340 & $0.0041 * *$ \\
\hline High Trades & 0.0143 & 0.0213 & $0.007 * * *$ & 0.0140 & 0.0144 & 0.0014 & 0.0141 & 0.0142 & 0.0001 \\
\hline \multicolumn{10}{|l|}{ Effective } \\
\hline Low Trades & 0.0076 & 0.0121 & $0.0045^{* * *}$ & 0.0334 & 0.0408 & $0.0074 * *$ & 0.0367 & 0.0428 & 0.0061 \\
\hline High Trades & 0.0030 & 0.0047 & $0.0017 * * *$ & 0.0103 & 0.0105 & 0.0003 & 0.0106 & 0.0109 & 0.0003 \\
\hline \multicolumn{10}{|l|}{ Price Impact } \\
\hline Low Trades & 0.0078 & 0.0121 & $0.0043 * * *$ & 0.0052 & 0.0064 & $0.0012 * * *$ & 0.0057 & 0.0063 & 0.0006 \\
\hline High Trades & 0.0048 & 0.0075 & $0.0028 * * *$ & 0.0030 & 0.0031 & 0.0001 & 0.0030 & 0.0033 & 0.0001 \\
\hline \multicolumn{10}{|l|}{ Prop of IA } \\
\hline Low Trades & 0.2542 & 0.3653 & $0.1111^{* *}$ & 0.2719 & 0.3240 & $0.0521^{* * *}$ & 0.2601 & 0.3183 & $0.0581 * *$ \\
\hline High Trades & 0.1460 & 0.2845 & $0.1385 * * *$ & 0.1937 & 0.2075 & 0.0134 & 0.2192 & 0.2179 & -0.0013 \\
\hline \multicolumn{10}{|l|}{ PIN } \\
\hline Low Trades & 0.2735 & 0.2429 & $-0.0306^{* *}$ & 0.2321 & 0.2700 & $0.379 * *$ & 0.2531 & 0.2868 & $0.0337 *$ \\
\hline High Trades & 0.1739 & 0.1951 & $0.0212 *$ & 0.1632 & 0.1970 & $0.0338 * *$ & 0.1814 & 0.1944 & 0.0130 \\
\hline \multicolumn{10}{|c|}{ Panel B: Sort by Pre-Change Information Asymmetry } \\
\hline \multicolumn{10}{|l|}{ Quoted Spread } \\
\hline Low IA & 0.0185 & 0.0263 & $0.0078 * * *$ & 0.0188 & 0.0225 & $0.0029 * *$ & 0.0179 & 0.0231 & $0.0052 * * *$ \\
\hline High IA & 0.0234 & 0.0372 & $0.0138 * * *$ & 0.0208 & 0.0232 & 0.0028 & 0.0193 & 0.0233 & $0.0055^{* *}$ \\
\hline \multicolumn{10}{|l|}{ Effective } \\
\hline Low IA & 0.0041 & 0.0063 & $0.0022 * * *$ & 0.0107 & 0.0120 & 0.0013 & 0.0102 & 0.0112 & 0.0010 \\
\hline High IA & 0.0066 & 0.0108 & $0.0042 * * *$ & 0.0591 & 0.0648 & 0.0046 & 0.0524 & 0.0642 & $0.0101 * *$ \\
\hline \multicolumn{10}{|l|}{ Price Impact } \\
\hline Low IA & 0.0055 & 0.0086 & $0.0031 * * *$ & 0.0038 & 0.0041 & 0.0003 & 0.0036 & 0.0040 & $0.0005^{* *}$ \\
\hline High IA & 0.0069 & 0.0113 & $0.0044 * * *$ & 0.0050 & 0.0054 & 0.0003 & 0.0044 & 0.0055 & $0.0011 * * *$ \\
\hline \multicolumn{10}{|l|}{ Prop of IA } \\
\hline Low IA & 0.1252 & 0.2601 & $0.1349 * * *$ & 0.1842 & 0.2055 & 0.0213 & 0.1670 & 0.2114 & $0.0444 * *$ \\
\hline High IA & 0.2886 & 0.3350 & $0.0464^{*}$ & 0.3242 & 0.3641 & 0.0163 & 0.3313 & 0.3498 & $0.0250^{*}$ \\
\hline \multicolumn{10}{|l|}{ PIN } \\
\hline Low IA & 0.1858 & 0.2019 & 0.0161 & 0.1997 & 0.2395 & $0.0398 * *$ & 0.1807 & 0.2317 & $0.0510 * * *$ \\
\hline High IA & 0.2628 & 0.2458 & -0.017 & 0.2311 & 0.2586 & $0.0275^{* *}$ & 0.2232 & 0.2512 & $0.0279 * *$ \\
\hline
\end{tabular}

Note: This table reports the change in information asymmetry measures for sorts on pre-change trading activity (Panel A) and sorts on prechange information asymmetry (Panel B). Quoted Spreads are calculated as the cross-sectional average of the bid-ask spread divided by the midpoint of the spread. Effective Spreads are calculated as the cross-sectional average of the transaction price less the midpoint of the spread divided by the midpoint of the spread. Price Impacts are calculated as the cross-sectional average of the midpoint of the spreads 5 minutes after a trade less the midpoint of the spread at the time of the trade divided by the midpoint of the spread at the time of the trade. Statistical significance is calculated using a matched-pairs t-test. Prop of IA is computed using the Lin et al. (1995) decomposition model and he Probability of Informed Trading is computed following Easley et al. (1996, 1997a, 1997b) and significance is assessed using a paired t-test. Significance at the $10 \%, 5 \%$, and $1 \%$ level is indicated by ***, and $* * *$, respectively. 
Table 4. Difference-in-Difference Analysis of Information Asymmetry Measures

\begin{tabular}{|c|c|c|c|c|c|c|c|}
\hline & Constant & $D^{N Z X}$ & $\Delta M V$ & $\triangle M B$ & $\Delta T / D$ & $\Delta$ Vola & $\overline{R^{2}}$ \\
\hline \multicolumn{8}{|c|}{ Panel A: Twelve-Month Window } \\
\hline \multirow[t]{2}{*}{$P S$} & $0.0125 * * *$ & $0.0175 * *$ & 0.0116 & 0.0089 & 0.0087 & 0.0016 & 0.1655 \\
\hline & $(0.004)$ & $(0.008)$ & $(0.015)$ & $(0.006)$ & $(0.010)$ & $(0.010)$ & \\
\hline \multirow[t]{2}{*}{$E S$} & $0.0045^{* * *}$ & 0.0089 & 0.0041 & 0.0044 & 0.0005 & 0.0058 & 0.0969 \\
\hline & $(0.001)$ & $(0.006)$ & $(0.005)$ & $(0.003)$ & $(0.004)$ & $(0.006)$ & \\
\hline \multirow[t]{2}{*}{$P I$} & $0.0040 * * *$ & $0.0036 * * *$ & 0.0024 & $0.0021 *$ & 0.001 & 0.0002 & 0.1851 \\
\hline & $(0.001)$ & $(0.001)$ & $(0.003)$ & $(0.001)$ & $(0.002)$ & $(0.002)$ & \\
\hline \multirow[t]{2}{*}{ PROP } & $0.1547 * * *$ & $0.1750 * * *$ & $0.1072 *$ & 0.003 & 0.0216 & 0.0161 & 0.2878 \\
\hline & $(0.031)$ & $(0.038)$ & $(0.055)$ & $(0.016)$ & $(0.057)$ & $(0.051)$ & \\
\hline \multirow[t]{2}{*}{ PIN } & -0.003 & $0.0446 * *$ & -0.0192 & 0.0106 & $0.0416 * *$ & -0.002 & 0.1246 \\
\hline & $(0.01)$ & $(0.02)$ & $(0.024)$ & $(0.009)$ & $(0.020)$ & $(0.024)$ & \\
\hline \multicolumn{8}{|c|}{ Panel B: Six-Month Window } \\
\hline \multirow[t]{2}{*}{$P S$} & $0.0036^{*}$ & 0.0071 & -0.0093 & 0.0146 & 0.0002 & 0.003 & 0.0992 \\
\hline & $(0.002)$ & $(0.005)$ & $(0.008)$ & $(0.013)$ & $(0.005)$ & $(0.004)$ & \\
\hline \multirow[t]{2}{*}{$E S$} & $0.0022 *$ & $0.0037 *$ & -0.0007 & 0.0074 & 0.0025 & -0.0008 & 0.0754 \\
\hline & $(0.001)$ & $(0.002)$ & $(0.004)$ & $(0.007)$ & $(0.002)$ & $(0.002)$ & \\
\hline \multirow[t]{2}{*}{$P I$} & 0.0000 & 0.0012 & $-0.0030 * *$ & 0.0049 & 0.0015 & 0.0006 & 0.1365 \\
\hline & $(0.000$ & $(0.001)$ & $(0.001)$ & $(0.003)$ & $(0.001)$ & $(0.001)$ & \\
\hline \multirow[t]{2}{*}{ PROP } & 0.0295 & $0.0822 *$ & -0.0821 & -0.0926 & 0.0265 & -0.0036 & 0.0581 \\
\hline & $(0.018)$ & $(0.044)$ & $(0.080)$ & $(0.161)$ & (0.059) & $(0.038)$ & \\
\hline \multirow[t]{2}{*}{ PIN } & $0.0276 * *$ & $0.0619 * *$ & 0.0318 & 0.069 & 0.0200 & -0.0291 & 0.1238 \\
\hline & $(0.013)$ & $(0.029)$ & $(0.063)$ & $(0.076)$ & $(0.036)$ & $(0.024)$ & \\
\hline \multicolumn{8}{|c|}{ onth Win } \\
\hline \multirow[t]{2}{*}{$P S$} & 0.0017 & $0.0069 * * *$ & -0.0031 & 0.0056 & -0.0115 & $-0.0053^{*}$ & 0.2286 \\
\hline & $(0.001)$ & $(0.003)$ & $(0.006)$ & $(0.004)$ & $(0.007)$ & $(0.003)$ & \\
\hline \multirow[t]{2}{*}{$E S$} & $0.0014 *$ & 0.0000 & 0.0018 & 0.0016 & $-0.0056 * * *$ & 0.0006 & 0.0955 \\
\hline & $(0.001)$ & $(0.001)$ & $(0.003)$ & $(0.001)$ & $(0.002)$ & $(0.001)$ & \\
\hline \multirow[t]{2}{*}{$P I$} & 0.0005 & -0.0004 & -0.0008 & 0.0009 & -0.0021 & 0.0014 & 0.0532 \\
\hline & $(0.000)$ & $(0.001)$ & $(0.004)$ & $(0.001)$ & $(0.002)$ & $(0.001)$ & \\
\hline \multirow[t]{2}{*}{ PROP } & 0.019 & $0.0970 *$ & -0.0642 & 0.0575 & 0.0622 & 0.005 & 0.0488 \\
\hline & $(0.023)$ & $(0.057)$ & $(0.180)$ & $(0.071)$ & $(0.098)$ & $(0.059)$ & \\
\hline \multirow[t]{2}{*}{ PIN } & 0.0126 & 0.0303 & -0.0168 & -0.0014 & -0.0192 & $-0.0501 * *$ & 0.1199 \\
\hline & $(0.012)$ & $(0.030)$ & $(0.082)$ & $(0.030)$ & $(0.049)$ & $(0.020)$ & \\
\hline
\end{tabular}

Note: This table reports the regression results for the difference-in-difference estimation. Regressions were conducted on 94 observations, the difference in the pre- and post-change values for 51 NZX companies and 43 ASX companies. In Panel A, B, and C we present the results for the twelve-, six- and three-month window before and after the enactment of the new legislation, respectively. The results are presented for the quoted spread $(Q S)$, effective spread $(E S)$, the price impact of trades $(P I)$, the proportion of information asymmetry $(P R O P)$, and the probability of informed trading $(P I N)$. The variable of interest is $D^{N Z X}$ which captures the effect of the change in legislation on the various information asymmetry measures. We control for the change in log market value $(\triangle M V)$, the change in market to book ratio $(\triangle M B)$, the change in the log of the trades per day $(\Delta T / D)$, and the change in the variance of stock returns $(\triangle$ Vola $)$. Robust standard errors are presented in parentheses. Significance at the $10 \%, 5 \%$, and $1 \%$ level is indicated by $*$, **, and ***, respectively. 
Table 5. Difference-in-Difference Analysis of Information Asymmetry Sorts

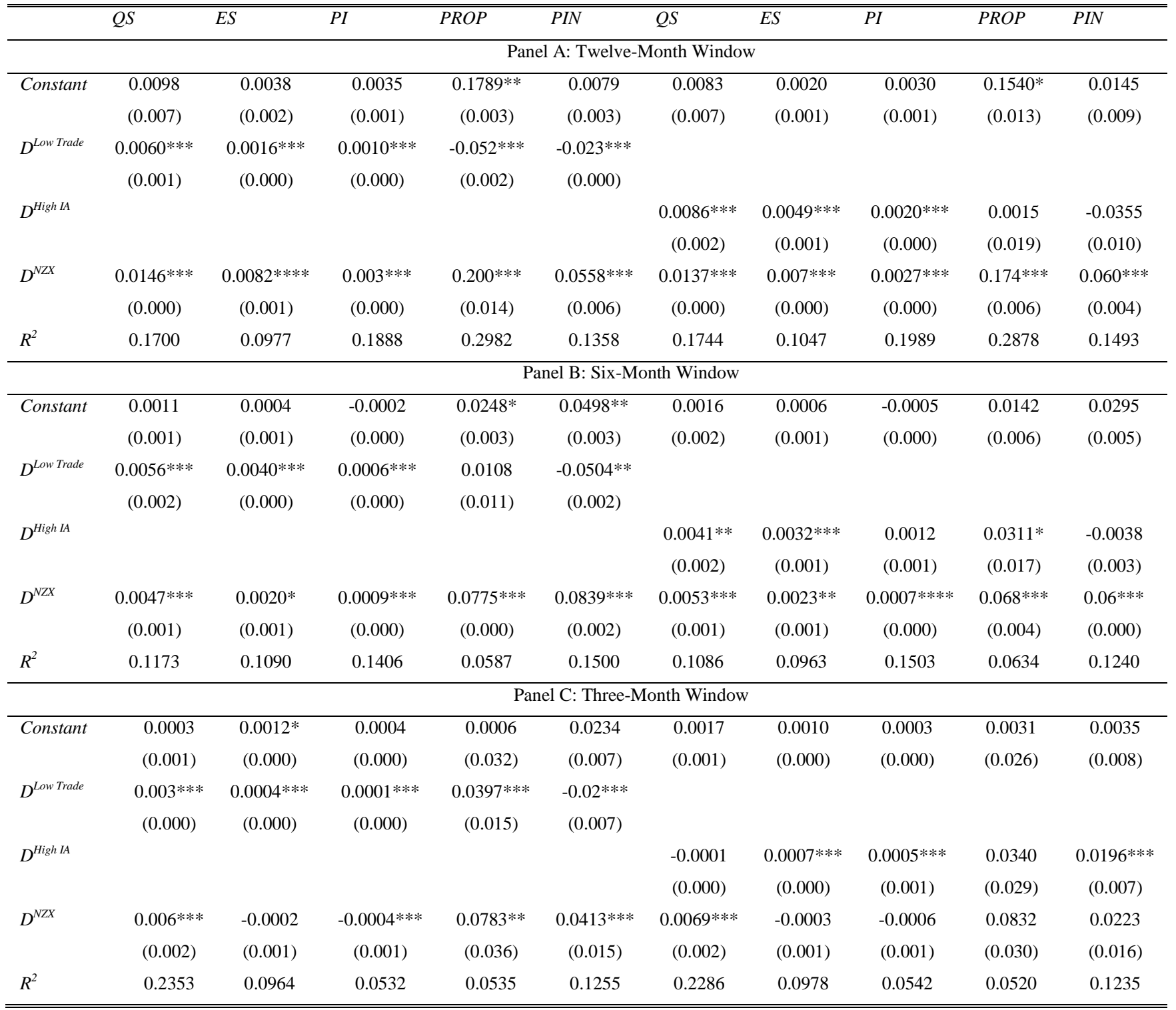

Note: This table reports the regression results for the difference-in-difference estimation of the information asymmetry sorts. Regressions were conducted on 94 observations, the difference in the pre- and post-change values for 51 NZX companies and 43 ASX companies. In Panel A, B, and C we present the results for the twelve-, six- and three-month window before and after the enactment of the new legislation, respectively. The results are presented for the quoted spread $(Q S)$, effective spread $(E S)$, the price impact of trades $(P I)$, the proportion of information asymmetry $(P R O P)$, and the probability of informed trading $(P I N)$. The variables of interest are $D^{\text {Low Trade }}$, which is a dummy that is equal to 1 for an illiquid NZX firm and zero otherwise, $D^{\text {High IA }}$, which is a dummy that is equal to 1 for an NZX firm has a high pre-change information asymmetry and $D^{N Z X}$, which captures the effect of the change in legislation on the various information asymmetry measures. We control for the change in log market value, the change in market to book ratio, the change in the log of the trades per day, and the change in the variance of stock returns, but do not report these results for the sake of brevity. Robust standard errors are presented in parentheses. Significance at the $10 \%, 5 \%$, and $1 \%$ level is indicated by *, **, and ***, respectively. 